Research Article

\title{
Fiber-Reinforced Magnesium Phosphate Cement-Based Nanocomposites in the Field of Bridge Structure Repair and Strengthening
}

\author{
Wenwei Yang $\mathbb{i D}^{1,2}$ \\ ${ }^{1}$ Lanzhou University, Ministry of Education of China, \\ Key Laboratory of Mechanics on Disaster and Environment in Western China, Lanzhou 730000, Gansu, China \\ ${ }^{2}$ Lanzhou University, Civil Engineering \& Mechanical College, Department Mechanical \& Engineering Science, Lanzhou 730000, \\ Gansu, China
}

Correspondence should be addressed to Wenwei Yang; yangwenwei@lzu.edu.cn

Received 10 May 2021; Revised 18 June 2021; Accepted 7 July 2021; Published 3 August 2021

Academic Editor: Wei Liu

Copyright (c) 2021 Wenwei Yang. This is an open access article distributed under the Creative Commons Attribution License, which permits unrestricted use, distribution, and reproduction in any medium, provided the original work is properly cited.

\begin{abstract}
Currently, fiber-reinforced magnesium phosphate cement-based nanocomposites are being used in various projects. The unique physical properties of this material allow it to bear the load together with the material in the inherent structure, and it will be better used in the field of bridge structure repair and reinforcement. The purpose of this article is to study the application of fiberreinforced magnesium phosphate cement-based nanocomposites in the field of bridge structure repair and reinforcement. Through the use of finite element analysis software and various stress sensor materials, the mechanical properties of fiberreinforced magnesium phosphate cement-based nanocomposites are used to analyze the mechanical properties of damaged bridges in our area after reinforcement treatment and establish a control group (using magnesium phosphate cement-based nanocomposite materials) for comparative experiments. The reinforcement effect of the bridge repair structure under different ballast conditions is studied. Studies have shown that fiber-reinforced magnesium phosphate cement-based nanocomposites can provide excellent reinforcement for damaged bridge structures. Compared to the control group, the strength and stiffness of the repaired structure were significantly improved, the strength increased by $15.7 \%$, and the stiffness increased by $12 \%$. The carrying capacity has also been improved compared to the previous one, from the original $120 \mathrm{t}$ to $150 \mathrm{t}$.
\end{abstract}

\section{Introduction}

Now there are more ways to strengthen concrete structures [1]. The design specification for reinforced concrete structures (GB50367-2013) introduces the specific ones: crack repair technology, pre-tensioned steel wire rope net, polymer mortar reinforcement method, anchor bolt technology, and pasted steel plate, and the reinforcement method of prestressed carbon fiber composite materials [2]. In addition, there are additional protection and reinforcement methods, replacement methods, steel wire reinforcement methods, reinforced concrete and prestressed reinforcement methods, reinforcement methods for steel bars and CFRP composite materials, cross-sectional expansion methods, etc. $[1,3]$.
Magnesium phosphate cement is a new type of environmentally friendly cementitious material. It is composed of magnesium oxide, soluble phosphate, and retarder according to an appropriate mixing ratio. Through acid-base neutralization reaction, a flowing acidic composite brine is generated [4]. In recent years, a new type of environmentally friendly cement material has received more and more attention, especially in the application of rapid restoration. After several years of research, development, and accumulation, MPC can gradually be divided into three categories: phospho-Portland cement (MPSC), magnesium ammonium phosphate cement (MAPC), and potassium magnesium calcium phosphate cement (MKPC) [5]. The cement chosen in this topic is potassium magnesium phosphate cement. The reinforced concrete method of fiber-reinforced potassium phosphate 
cement mortar is similar to that of reinforced concrete with enlarged section.

The purpose of this article is to study the effect of fiberreinforced magnesium phosphate cement-based nanocomposites on bridge structure repair. Among them, Ahmad pointed out in the article that in the repair of damaged bridge structures, the repair effects of various existing materials are not very good, the cost of repair materials is often too high, and new materials are urgently needed in the field of bridge construction to be replaced [6]. Peters' et al. research found that magnesium phosphate cement-based nanocomposites have excellent effects in repairing various damaged beam structures, and the manufacturing cost is still acceptable [7]. Selvakumar et al. conducted various mechanical performance experiments on magnesium phosphate cement-based nanocomposites and found that adding various materials to it can better improve this mechanical performance [8]. Díez -Pascual and Díez-Vicente found through experiments that adding a certain amount of fiber to the magnesium phosphate cement-based nanocomposite material can well increase the tensile and compressive strength of the material [9]. Li et al. found that the fiberreinforced magnesium phosphate cement-based nanocomposite has an excellent repair effect on the bridge structure, the strength and rigidity of the repaired structure are significantly improved, and the bearing capacity is also improved compared with the previous one [10].

In the research on the application of fiber-reinforced magnesium phosphate cement-based nanocomposites in the field of bridge structure repair and reinforcement, this article summarizes and compares the research status and research results of previous scholars and material scientists. This article is innovative. The points are roughly as follows. First, this article uses finite element analysis software and various stress sensor materials for the first time to conduct a detailed analysis of the stress-carrying capacity of the material in the damaged structure of the bridge and verifies the feasibility of the material. The second point is that this paper strictly established a control experiment through the controlled variable method. The experimental group uses fiber-reinforced magnesium phosphate cement-based nanocomposites, and the control group uses magnesium phosphate cement-based nanocomposites. A two-month experiment was carried out. Variables are strictly controlled to ensure the accuracy of the experiment. The third point is that this paper not only analyzes the physical properties of the material in detail but also conducts an experimental analysis on the influence of the amount of fiber on the reinforcement effect and examines the fiber ratio of the composite material when the physical properties are optimal.

\section{Research Content of Fiber-Reinforced Magnesium Phosphate Cement- Based Nanocomposites}

2.1. Characteristics and Application Fields of Magnesium Phosphate Cement. Magnesium phosphate cement, as an environmentally friendly cementing material with chemical bonding ceramic properties, has characteristics that other existing building materials cannot match, for example, fast setting speed, demoulding within 30 minutes [11], and high strength, the strength can reach more than $40 \mathrm{MPa}$ within 3 hours [12]; at the same time, it has good compatibility with old concrete and high bonding strength. It has excellent wear resistance, which is twice that of ordinary Portland cement products and can be used as a repair material. Under the same conditions, steel bars have better rust resistance, and the corrosion rate of steel bars is only $22.8 \%$ of that of ordinary Portland cement [13]. Its excellent salt resistance and antifreeze corrosion properties make the phosphate cement mortar and concrete surface to spall off only after 40 years. It has good heat resistance and can withstand high temperatures of $1300^{\circ} \mathrm{C}$ [14].

Various waste materials that can be used for cement not only are environmentally friendly but also can reduce costs and improve the performance of cement slurry.

At present, the use and development of MPC are mainly concentrated in the following parts.

2.1.1. As a Quick Repair Material. In terms of road maintenance, disc acid magnesium cement not only can be quickly set and formed but also has high early strength. The construction process is simple, the maintenance is convenient, and it has superior durability. It can be constructed even in low temperature environments. It is an ideal rapid road repair material; it has become the most common application of magnesium phosphate cement today [15].

2.1.2. Solidified Body as Hazardous Waste. The nuclear waste produced by magnesium phosphate cement can be treated by radiation curing at room temperature without a special calcining device, which not only reduces fuel costs but also avoids secondary pollution caused by waste components in volatiles. At the same time, the waste product has high strength, good stability, and low dissolution rate of environmental pollution or human body-damaging substances, which is a very promising curing method.

When a material containing harmful substances is added to magnesium phosphate cement, it reacts with the hydration product of magnesium phosphate cement to produce new phosphoric acid. These phosphates have low solubility and are tightly wrapped by the hydrated product of magnesium phosphate cement.

2.1.3. As a New Type of Adhesive Made of Artificial Wood. Magnesium phosphate cement replaces the existing adhesives for wood-based panels. Compared with the existing production process, magnesium phosphate cement can effectively reduce energy consumption, control the emission of harmful environmental substances, and make woodbased panels more prominent in fire resistance and durability. After mixing magnesium phosphate cement and lignin waste particles uniformly, the hydration reaction generates phosphate, which cements the lignin waste into a network to form a composite material with significant 
compactness [16]. This process can quickly cure and harden at room temperature without heating and curing like traditional polymers, and there is no special requirement for environmental humidity.

2.1.4. Production of Biological Bone Cement. Magnesium phosphate cement is non-toxic, has excellent biocompatibility, and has a good gelation effect between biological bones. It enters the biological body without foreign body reaction, so biological bone cement can be made into a rapid repair material for bone fixation of teeth and has a good development prospect in the medical field [17].

2.1.5. As Paint Material. Due to the rapid early strength and excellent fire resistance of magnesium phosphate cement, some American companies have developed sprayed concrete, which can be sprayed directly on the surface of rigid foam polystyrene boards or wood to form a complete wall mode.

2.2. Advantages and Disadvantages of Fiber-Modified Magnesium Phosphate Cement. Carbon fiber-modified magnesium phosphate cement is a magnesium phosphate cementbased composite material based on magnesium phosphate cement, in which discontinuously cut carbon fibers are added as a reinforcing and toughening material. The carbon fiber added to the magnesium phosphate cement matrix has the following function: to improve the tensile strength of the matrix. Internal defects are the predisposing factors leading to the failure of magnesium phosphate cement [1]. In order to improve the tensile strength, it is necessary to minimize the stress concentration at the internal fracture end and limit the fracture propagation. The uniform and arbitrary distribution of short-cut carbon fibers in carbon fiber-modified magnesium phosphate cement improves the matrix structure of magnesium phosphate cement, reduces defects in the matrix, and improves the continuity of the magnesium phosphate cement matrix during concrete hardening [18]. During the stress process of the magnesium phosphate cement, the carbon fiber and the magnesium phosphate cement matrix deform together under the action of the stress, and the bridging effect of the carbon fiber makes the magnesium phosphate cement continuously crack and bear greater load. All these contribute to improving the tensile strength of carbon fiber-modified magnesium phosphate cement [19].

The addition of carbon fiber is like adding a large number of thin strips to the matrix, forming a relatively complete network structure. During the development process, the microcracks are inevitably blocked by carbon fiber, which hinders the propagation of the cracks, thereby playing a role in crack resistance. The fiber is closely combined with the matrix material, which greatly maintains the overall strength of the magnesium phosphate cement [20]. When a wall made of concrete receives an impact, carbon fiber will absorb a lot of energy, thereby effectively reducing the impact of stress concentration. Carbon fiber has a bridging effect on the fracture of magnesium phosphate cement and consumes energy when the fiber is pulled out of the matrix of magnesium phosphate cement [21]. All of the above effects help improve the toughness of concrete. Carbon fiber is more effective than magnesium phosphate cement, but the surface of the carbon fiber has a graphite structure [22]. Due to its smooth surface, such as inertness, the number and types of active functional groups are small, and the composite with magnesium phosphate cement has poor interface bonding. The interlayer shear strength of cement paste is low, and the pull-out resistance of carbon fiber is poor $[2,23]$. Therefore, in order to improve the toughening effect of magnesium phosphate cement fiber, surface modification of carbon fiber is required.

\subsection{Effect of Fiber on the Properties of Magnesium Phosphate} Cement. Magnesium phosphate cement is composed of reburned magnesium oxide, soluble phosphate, and retarder. The main hydration product is magnesium ammonium phosphate hexahydrate, which has the advantages of fast solidification, fast hardening, and high early strength [24]. It can be used for rapid repair of concrete roads and structures and radioactive and toxic curing treatments [25]. However, since the main cohesive forces of magnesium phosphate cement are ionic bonds and covalent bonds, its brittleness is relatively large, so it needs to be toughened and modified. At present, the main toughening modification measures are polymer emulsion modification and fiber modification. Studies have shown that polymer emulsions can encapsulate magnesium oxide particles, which has an adverse effect on the hydration process and the strength of magnesium phosphate cement, so it is rarely used [26]. Fiber modification mainly uses organic fibers, glass fibers, steel fibers, carbon fibers, etc. Among them, carbon fibers have the advantages of high modulus, high tensile strength, and good corrosion resistance. The toughening effect of magnesium phosphate cement is particularly obvious [27]. In the laboratory, according to the mixing ratio of magnesium phosphate cement mortar and carbon fiber, the length and content of carbon fiber, and the water-cement ratio studied, the expansion degree of magnesium phosphate cement mortar was studied. According to the hardening strength of magnesium phosphate cement, the dispersion of carbon fiber in magnesium phosphate cement mortar was also studied, and its compressive strength, flexural strength, and split tensile strength were analyzed [28].

Since magnesium phosphate cement is not used in industrial production, this article uses a mixture of magnesium phosphate cement for a variety of raw materials, including soluble phosphate using ammonium dihydrogen phosphate, retarder using borax, the proportion of magnesium oxide concrete, and ammonium dihydrogen phosphate $=4: 1$; the sand content of borax (calculated by the mass of magnesium oxide): magnesium oxide $=1: 10$ [29]. Good workability is an important indicator for evaluating the performance of concrete and mortar. The lap and agglomeration of fibers will greatly reduce the fluidity and performance of concrete. This section mainly studies the influence of fiber length, water-cement ratio, and fiber content on the working performance of magnesium phosphate cement mortar, which is characterized by the swelling degree of the mortar. In the 
test, the sand-to-cement ratio of the magnesium phosphate cement mortar is $1: 1$, and the fibers are $3 \mathrm{~mm}, 6 \mathrm{~mm}$, $10 \mathrm{~mm}$, and $15 \mathrm{~mm}$, respectively [30]. Fiber content is all volume content. The light weight of carbon fiber is less than half the density of magnesium oxide, and the surface is hydrophobic. In addition, the diameter of the fiber is much smaller than that of magnesium oxide and fine aggregate particles, so it is difficult to uniformly mix carbon fiber and magnesium phosphate cement mortar. When carbon fiber is added to magnesium phosphate cement to improve its toughness, in order to give full play to its high modulus and high tensile strength, it must be uniformly dispersed in the mortar. When the dispersion performance of carbon fibers is poor, the strength of magnesium phosphate cement mortar is easily affected by the fiber dispersion state of the worst part and the dispersion of carbon fibers, and the local content of the dominant part is too small. The elongation strength fails to give full play to the advantages of high, so the uniformity of the carbon fiber dispersion determines its effect on improving the toughness of magnesium phosphate cement mortar [31].

\section{The Experiment of Fiber-Reinforced Magnesium Phosphate Cement-Based Nanocomposite in Bridge Structure Repair}

3.1. Materials Needed for Experimental Cement. The prepared material is calcined at a high temperature to form magnesium oxide. The material is purchased from Jiangsu Huanan Magnesium Industry Co., Ltd., and the production process adopts a two-step calcination method. First, magnesite is processed at about $1000^{\circ} \mathrm{C}$ to obtain light-burned magnesia and then calcined at a high temperature of $1700^{\circ} \mathrm{C}$ for 6 hours to obtain reburned magnesia. The recalcined magnesia used in the test was first ground by a ball mill and then sieved through a sieve with an aperture of $0.1 \mathrm{~mm}$ to a specific surface area of $310-3202 \mathrm{~m} / \mathrm{kg}$. The content of each component of the purchased dead-burned magnesia is shown in Table 1.

In addition, there are two types of potassium dihydrogen phosphate (KDP) raw materials used for testing. The first raw material was purchased from Tianjin Dongsheng Chemical Co., Ltd., the registration number was KDP-1, and the crystal size was $28 / 600 \sim 35 / 425 \mathrm{mesh} / \mathrm{m}$. The second raw material was provided by Fujian Waiting Chemical Co., Ltd. The crystal size was 48/315 80/180 mesh/m. The phosphate used in the experiment was obtained by uniformly mixing two potassium dihydrogen phosphates at a mass ratio of $1: 1$. All KDPs used are white crystals, easy to go crazy, and packed in plastic bags.

3.2. Experimental Nanomaterials and Other Admixtures. The nano iron oxide (NF) used in this test has a red powder appearance and was purchased from Ziti Nanometer Technology Co., Ltd. The main component is $\mathrm{Fe}_{2} \mathrm{O}_{3}$ $(\geq 99.8 \%)$, the particle size range is $20-50 \mathrm{~nm}$, and the specific surface area is $80-902 \mathrm{~m}^{2} / \mathrm{g}$. The nano alumina (NA)
TABLE 1: Data of neurotransmitter substances in plasma of control experiment.

\begin{tabular}{lccccc}
\hline Ingredient & $\mathrm{MgO}$ & $\mathrm{CaO}$ & $\mathrm{Fe}_{2} \mathrm{O}_{3}$ & $\mathrm{Al}_{2} \mathrm{O}_{3}$ & $\mathrm{SiO}_{2}$ \\
\hline Content (\%) & 97.5 & 0.15 & 0.05 & 0.03 & 0.02 \\
\hline
\end{tabular}

used in the test has an appearance of white powder and was purchased from Ziti Nano Technology Co., Ltd. The main component is $\mathrm{Al}_{2} \mathrm{O}_{3}(\geq 99 \%)$, the particle size range is $30-40 \mathrm{~nm}$, and the specific surface area is $2002 \mathrm{~m}^{2} / \mathrm{g}$ [32]. The sodium silicate glass (marked as WG) used in the experiment was white powder and was purchased from Tianjin Davao Chemical Reagent Factory. Its main component is $\mathrm{Na}_{2} \mathrm{SiO}_{3} \mathrm{H}_{2} \mathrm{O}(\geq 99 \%)$. The fiber (marked as $\mathrm{SF}$ ) used in the experiment was off-white and was purchased from Jinmen water purification material Co. The main component is $\mathrm{SiO}_{2}$ $(\geq 85 \%)$, the particle size is 2000 mesh, and the specific surface area is $20 \sim 282 \mathrm{~m}^{2} / \mathrm{g}$.

Four types of fiber (denoted as F) are used in this test: imitation steel fiber (denoted as ISF), microsteel fiber (denoted as MSF), flat steel fiber (SF), and tail hook steel fiber (HF). The imitation steel fiber was purchased from Ningbo Shake New Material Technology Co., Ltd. The material used is rough polypropylene, the surface is embossed, the cross section is rectangular, and the equivalent diameter is $0.6 \mathrm{~mm}$. The fine steel fiber was purchased from Shanghai Zhenjiang Fiber Co., Ltd. The material is stainless steel, the surface is plated with copper, the surface is smooth, the cross section is circular, and the equivalent diameter is $0.22 \mathrm{~mm}$. The straight steel fiber is obtained by removing the ends of the hookshaped steel fiber produced by Shanghai Bekaert. The tail hook steel fiber was purchased from Shanghai Bekaert Co., Ltd. It is a row of steel fibers, made of stainless steel, with a straight surface and curved ends.

3.3. Mechanical Performance Test of Magnesium Phosphate Cement Mortar. The compressive strength of magnesium phosphate cement mortar is tested by mechanical performance test, and its compressive strength test refers to ASTM C109 "Standard Test Method for Compression of Hydraulic Cement Mortar." The instruments and equipment used include cement mortar mixer $(5 \mathrm{~L})$, pressure testing machine $(200 \mathrm{~T})$, concrete magnetic vibration table, etc.

The measurement method of this test is as follows:

(1) The three joints of plastic compressed concrete were tested to form a cement mortar test block with a size of $50 \mathrm{~mm} \times 50 \mathrm{~mm} \times 50 \mathrm{~mm}$, which was taken out after being placed in the room and cured for 2 hours.

(2) Curing to the specified conditions according to the corresponding immersion time.

(3) According to the standard compressive strength test method, the loading speed of the compression testing machine is set to $0.9 \mathrm{kN} / \mathrm{s}$. Three samples are taken from each group to test and record the data. 
The load-displacement curve of the bonding performance between the fiber and the magnesium phosphate cement mortar was obtained through the fiber pull-out test. The bonding performance is tested with reference to "Test Method for Steel Fiber Concrete" (CECS13:2009). Compared with single fiber pull-out, the result of multi-fiber pullout test shows that the dispersion is smaller, and too small fiber spacing will reduce the bonding efficiency. Therefore, in this test, four fibers were pulled out in one direction, and the fiber interval was set to $12 \mathrm{~mm}$. The main instruments and equipment used are cement slurry mixer $(5 \mathrm{~L})$, electronic universal testing machine $(5 \mathrm{KN})$, pressure sensor $(2 \mathrm{KN})$, strain displacement sensor $(30 \mathrm{~mm})$, and No. 3 static strain testing system machine [33].

3.4. The Principle of Experimental FRCC Enhancement. The strengthening mechanism of FRCC mainly includes fiber spacing theory, composite mechanics theory, and multiple fracture theory. According to mechanics theory, composite materials are a combination of fibers and substrates, and according to the law of mixing, the overall performance of composite materials is equal to the sum of the properties of substrates and fibers. In order to calculate the fiber spacing $S$, it is considered that the fibers are distributed in a square ratio. On the basis of theoretical and experimental research, an algorithm for the average fiber spacing $S$ is established as shown in the following formula:

$$
S=13.8 * d * \sqrt{\frac{1}{P}}
$$

where $D$ is the diameter of the fiber; $P$ is the percentage of the fiber volume ratio; and $V_{f}$ is the volume fraction of the fiber.

The concept of effective spacing coefficient not only is a statistical description of the spacing between fiber centers but also points out the bad mode of fiber-matrix interaction, and its expression should include the factor of fiber shape. Therefore, the effective fiber spacing is also determined as shown in the following equation:

$$
S=25.0 * \sqrt{\frac{d}{P l}}
$$

where $S$ is the length of the fiber.

3.5. Experimental Process and Results. The surface treatment methods of old concrete are three treatment methods: without surface cleaning, mechanical chiseling to remove laitance, and chisel out by hand. For the mechanical gouging samples, the surface laitance is mainly removed by the gouging machine, while the artificial gouging is the gouging of the cement stone on the concrete surface, so that the coarse aggregate is exposed on the surface. The roughness of concrete measured by sand casting method is $1 \mathrm{~mm}$ and $4 \mathrm{~mm}$, respectively. Drilling holes and bolts used for insertion and positioning are MKPC cement positioning bolts, reinforced MKPC cement positioning bolts, and embedded steel bars. The electric drill is used to drill a $20 \mathrm{~mm}$ round hole with a depth of $3 \mathrm{~cm}$ on each of the two reinforced surfaces of the old concrete. The sample is B6, which is inserted into the hole and then the rubber is injected. The sampling material is made of steel wire mesh, which is inserted into a hole in old concrete and injected with MKPC grout, and the exposed steel wire is transferred and expanded. After treating the surface of the old concrete, pour MKPC cement mortar on both sides of the sample for double-sided reinforcement. Before pouring the MKPC mortar, the MKPC cement paste with a water-cement ratio of 0.12 was applied to the surface of the old concrete in a thickness of about $5 \mathrm{~mm}$. In order to avoid local breakage of the bonding layer by shearing the experimental pad, the thickness of the entire reinforcement layer is about $30 \mathrm{~mm}$. There are 3 specimens in each group, totaling 18 specimens. After curing for 28 days, a double-sided shear test was performed. At present, China does not have a unified interface shear strength test method standard.

Test Method. Reinforce the sample directly on both sides of the old concrete and conduct a double-sided shear test on the bonding surface between the reinforcement layer and the old concrete. The shear specimen is broken and the test is stopped. In order to eliminate the gap between the sample and the device and set the value of the tester to zero, the data are unreasonably omitted due to the possible stress imbalance during sample loading [34]. Finally, the shear strength of each group is obtained from the average value of each group of data.

\section{Effect of Fiber-Reinforced Magnesium Phosphate Cement-Based Nanocomposite on Bridge Structure Repair and Reinforcement}

4.1. Analysis of Influencing Factors of Compressive Strength of Fiber-Reinforced Magnesium Phosphate Cement-Based Nanocomposites in Repair and Strengthening of Bridge Structure. Analysis of influencing factors of compressive strength of fiber-reinforced magnesium phosphate cementbased nanocomposites in repair and strengthening of bridge structure is shown in Table 2 .

By comparing the data of each group in the above table, before the reinforcement, the cracking load of each beam is basically the same because it is not reinforced before the failure. By comparing the cracking load of the reinforced layer after A0-1 and A0-2 reinforcement, it can be seen that as the length of the reinforced layer increases, the cracking load of the damaged layer increases by $21.5 \%$. The main reason is that the reinforcement layer and the original structure coordinate share part of the section bending moment, thereby increasing the cracking load. Comparing the ultimate load of beam A0-0, beam $\mathrm{A} 0-1$ and beam $\mathrm{A} 0-2$ increase by $60.0 \%$ and $29.4 \%$, respectively. It can be seen that the longer the reinforced length after reinforcement, the better the lifting capacity of the ultimate load of the beam. Even if the length of the steel bar is 
not enough to withstand shear failure, the final load will still increase to a certain extent.

After the $\mathrm{pH}$ of the system reaches $>7, \mathrm{MKP}$ begins to precipitate rod-shaped crystals, which overlap each other to form a network structure, and the slurry condenses to finally form a hardened body with $\mathrm{MgO}$ particles as the skeleton and MKP crystals as a binder. The relevant data are shown in Figure 1.

It can be seen from the data in Figure 1 that $P / M$ affects the compressive strength of fiber-reinforced magnesium phosphate cement-based nanocomposites in the repair and reinforcement of bridge structures [35]. When the $P / M$ value increases to 0.3 , the material is used in the bridge structure. The compressive strength in repair and reinforcement was increased from $420 \mathrm{MPa}$ to $485 \mathrm{MPa}$, and the tensile strength was increased by $18 \%$.

The research results show that for ordinary Portland cement mortar, excessive water-cement ratio will cause seepage segregation of the new slurry, leaving large pores after hardening, which greatly affects the strength of the sample. Although the reaction mechanism of the magnesium phosphate cement system is different from that of ordinary Portland cement, a too large water-cement ratio will cause a large number of holes to be formed after the slurry hardens, and the structure is not dense enough, thereby reducing the strength. As $W / C$ increases from 0.24 to 0.30 , the $3 \mathrm{D}$ compressive strength of FMPM gradually decreases. The increase in $W / C$ allows the hydration reaction of the slurry to proceed completely, but the evaporation of excess water significantly increases the proportion of harmful pores in the cured product, resulting in a porous structure of the hydrated product. However, a too low waterbinder ratio is not only unfavorable to the formation of the slurry but also affects the progress of the test due to the short solidification time of the slurry; the specific data are shown in Figure 2.

It can be seen from the data in Figure 2 that the $W / C$ value affects the compressive strength of fiber-reinforced magnesium phosphate cement-based nanocomposites in the repair and reinforcement of bridge structures. When $W / C$ increases from 0.24 to 0.30 , the material is used in bridges. The compressive strength in structural repair and reinforcement was increased from $420 \mathrm{MPa}$ to $490 \mathrm{MPa}$, and the tensile strength was increased by $19.5 \%$.

4.2. Calculation and Analysis of Flexural Strength of FiberReinforced Magnesium Phosphate Cement-Based Nanocomposite in Repair and Strengthening of Bridge. The reason that affects the bending strength of FMPM is because the two basic mechanical properties of FMPM, namely, flexural strength and compressive strength, are mutually operable. Although there is no direct relationship between the two, the overall trend is similar. The first three factors are the main influencing factors; other factors will not be analyzed temporarily. The flexural strength of FMPM first increases, then decreases with $P / M$ from $1 / 2$ to $1 / 5$, then decreases with $W / C$ from 0.24 to 0.30 , and then decreases with S/C from 0.6 to 1.2. Single-doped fibers have similar effects on the bending strength and compressive strength of FMPM. For the bending strength, when the fiber content is $5 \%$, the $3 \mathrm{D}$ bending strength of FMPM increases by $4 \%$ compared with the reference group.

The strength will increase more obviously, and when the age is 14 days, the bending strength will increase by $17 \%$. When the fiber content is $10 \%$, the $3 \mathrm{~d}$ flexural strength of FMPM is increased by $9 \%$ compared with the reference group, $36 \%$ at $7 \mathrm{~d}$, and the highest value of $9.15 \mathrm{MPa}$ at $14 \mathrm{~d}$, which is 45 higher than the reference group. This also shows that, over time, the bending strength of FMPM will also greatly increase. However, when the fiber content was increased to $20 \%$, the improvement did not increase further, and the value of the flexural strength decreased relative to the group with the fiber content of $10 \%$. As for the compressive strength, when the fiber content is $5 \%$, the $3 \mathrm{D}$ compressive strength of FMPM does not change much and is $2 \%$ higher than the reference group. However, with the increase of age, the enhancement effect becomes more obvious, and the compressive strength of $14 \mathrm{~d}$ increases by $18 \%$. When the fiber content is $10 \%$, the $14 \mathrm{~d}$ compressive strength value is $44.35 \mathrm{MPa}$, which is $22 \%$ higher than the reference group. When the fiber content is $20 \%$, the compressive strength decreases to a certain extent. The relevant data are shown in Figure 3.

It can be seen from the data in Figure 3 that as the amount of fiber increases, the flexural strength and compressive strength of magnesium phosphate cement-based nanocomposites in the repair and reinforcement of bridge structures gradually increase, and the tensile strength and flexural strength are increased compared with general materials by $25 \%$.

The flexural strength of concrete beams and columns reinforced with inorganic basalt magnesium phosphate fiber can be increased by $57.5 \%$, and the ultimate axial compressive strength can be increased by $45.4 \%$. Adding an appropriate amount of fly ash to the magnesium phosphate cement can make the structure of the magnesium phosphate cement denser and increase the tensile strength of the fiber reinforced in the MPC matrix by about $10 \%$; at the same time, the binding force between the MPC and the matrix is improved, and the fiber structure is optimized. The specific data are shown in Figure 4.

It can be seen from Figure 4 that the strength and rigidity of the repaired structure have been significantly improved, among which the strength of the structure has increased by $15.7 \%$ and the rigidity has increased by $12 \%$. The carrying capacity has also been improved from the previous $120 \mathrm{t}$ to $150 \mathrm{t}$. 
TABLE 2: Summary of damaged beam bearing capacity.

\begin{tabular}{lccc}
\hline Beam number & Damage-cracking load & Cracking load of reinforcement layer & Ultimate load \\
\hline AO-0 & 17.23 & - & 35.69 \\
AO-1 & 16.12 & 28.65 & 62.15 \\
AO-2 & 15.23 & 24.65 & 45.36 \\
\hline
\end{tabular}

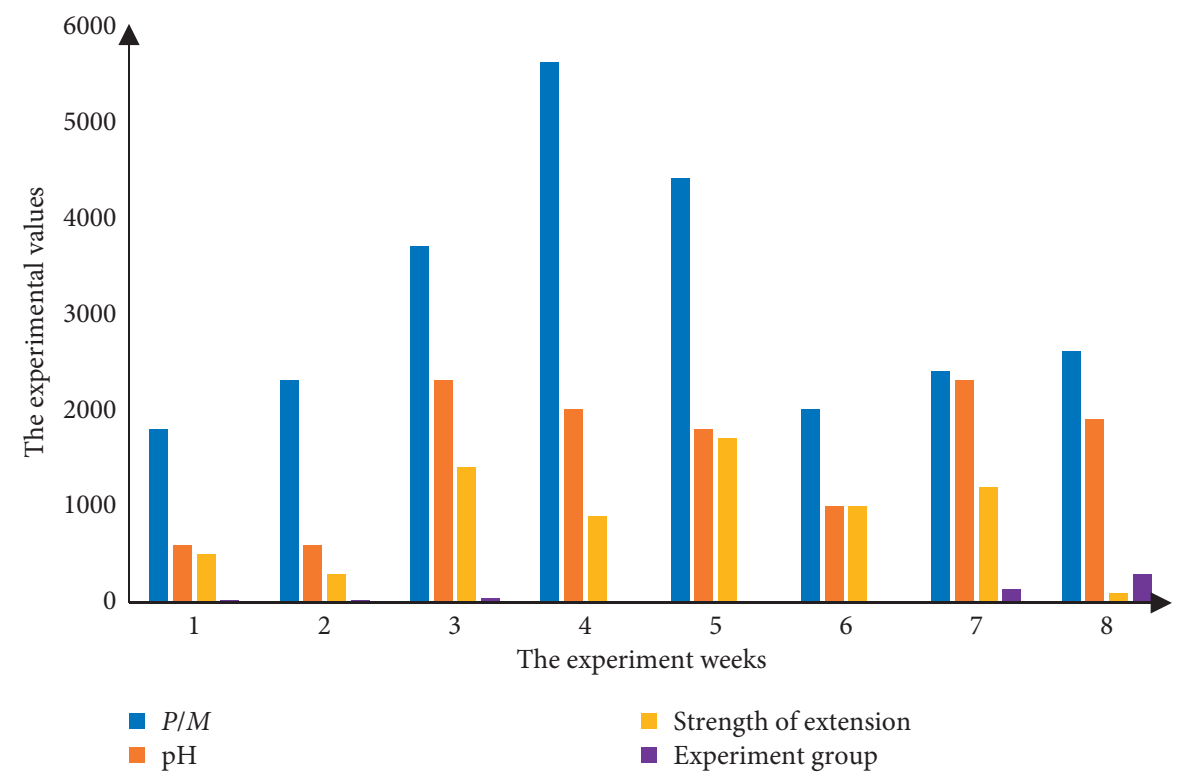

Figure 1: Effect of $P / M$ on compressive strength of fiber-reinforced magnesium phosphate cement-based nanocomposites in bridge structure repair and reinforcement.

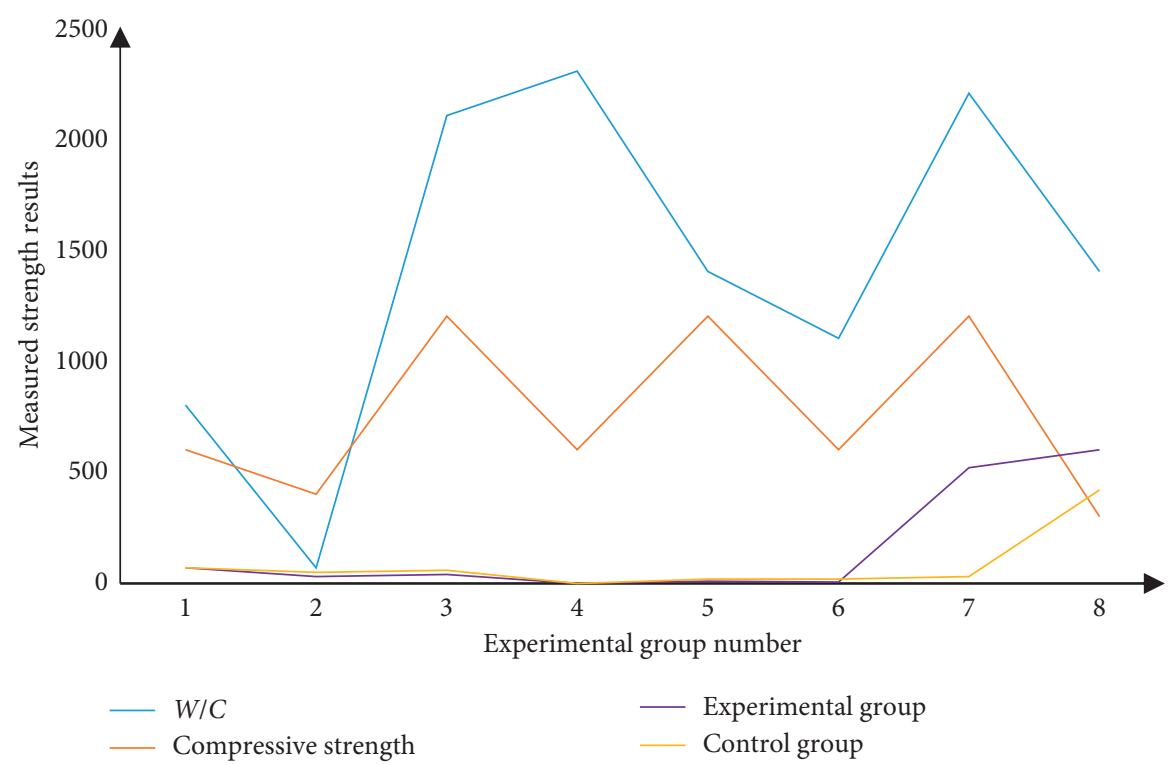

Figure 2: The effect of $W / C$ value on the compressive strength of fiber-reinforced magnesium phosphate cement-based nanocomposites in bridge structure repair and reinforcement. 


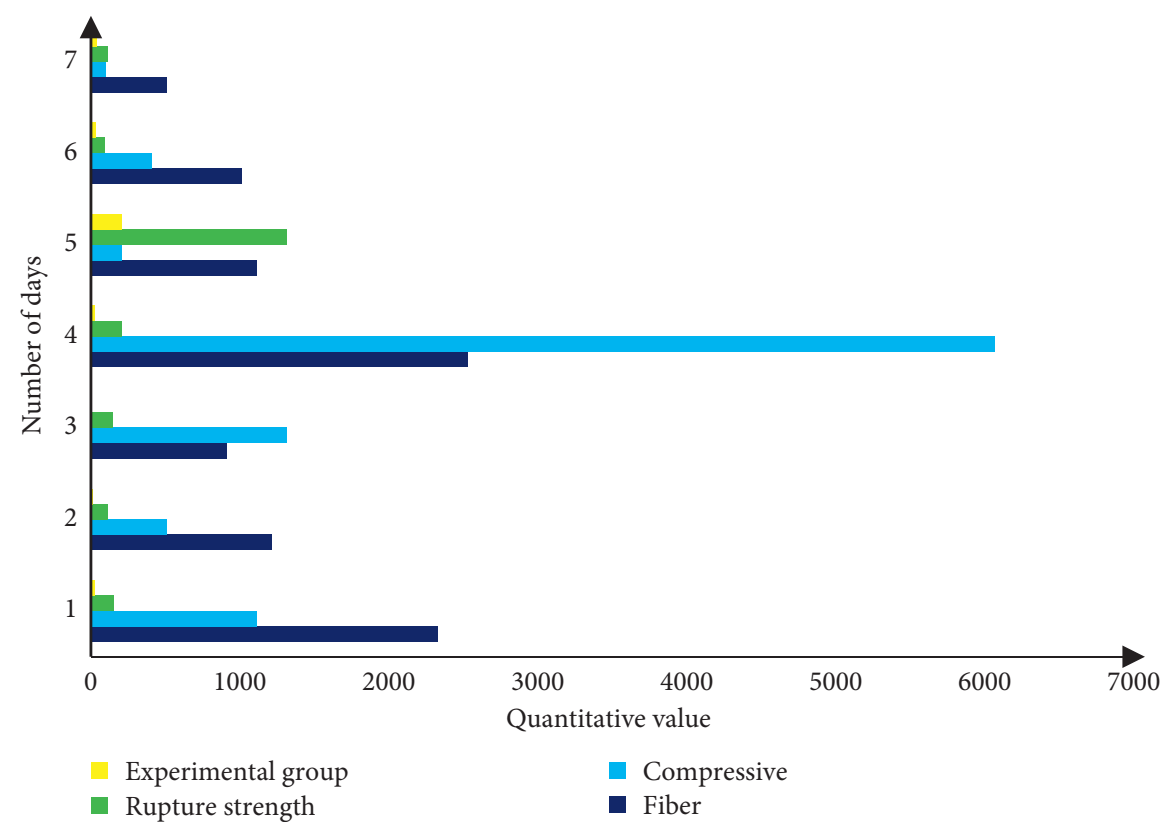

FIgURE 3: The enhancement of the fiber content to the flexural strength and compressive strength of magnesium phosphate cement-based nanocomposites.

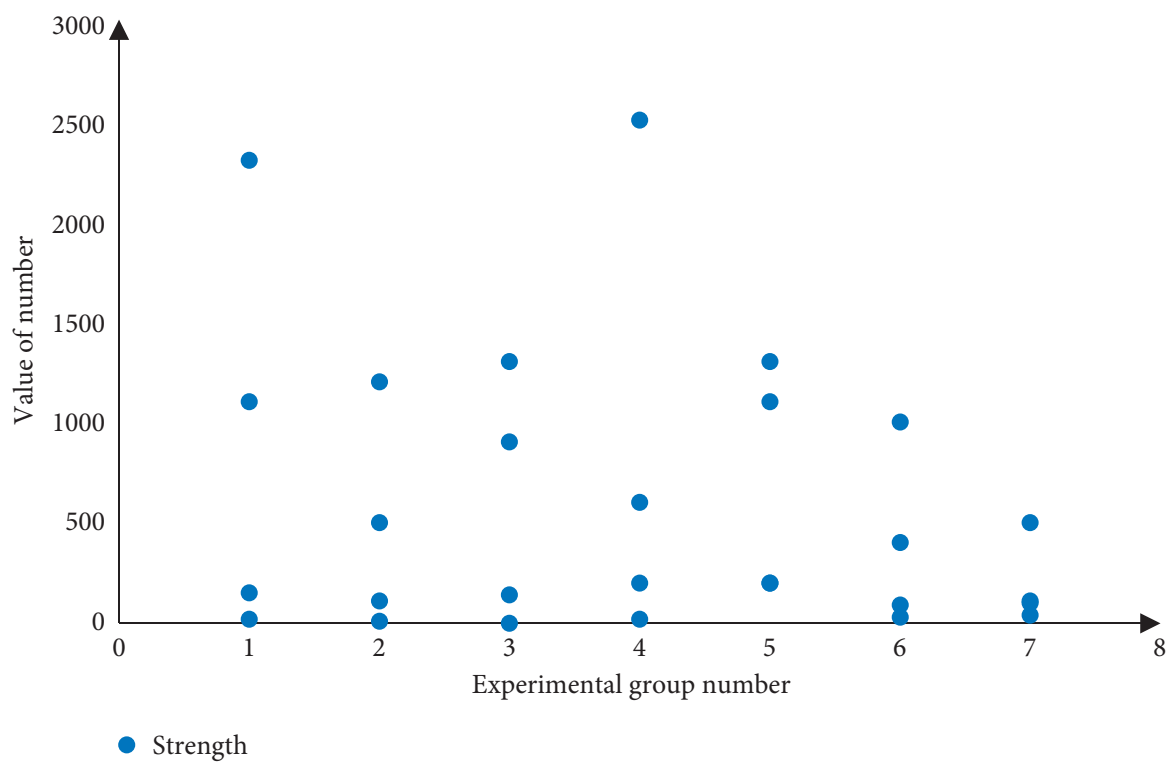

FIgURE 4: Repair effect of fiber-reinforced magnesium phosphate cement-based nanocomposite.

\section{Conclusions}

(1) This paper analyzes the current problems in the application of fiber-reinforced magnesium phosphate cement-based nanocomposites in the field of bridge structure repair and reinforcement, discusses to solve these problems, and proposes corresponding solutions. The common methods and materials for repairing and strengthening bridge structures are introduced, especially the mechanism of using mag- nesium phosphate cement-based nanocomposites to strengthen and repair bridge structures is discussed and introduced in detail.

(2) We analyzed the factors affecting the compressive strength of the fiber-reinforced magnesium phosphate cement-based nanocomposites in the bridge structure repair and reinforcement. Experiments have shown that $P / M$ affects fiber-reinforced magnesium phosphate cement-based nanocomposites 
with bridge structures. When the $P / M$ value increases to 0.3 , the compressive strength of the material in the repair and reinforcement of bridge structure increases from $420 \mathrm{MPa}$ to $485 \mathrm{MPa}$, and the tensile strength increases by $18 \%$.

(3) The calculation of flexural strength of fiber-reinforced magnesium phosphate cement-based nanocomposites in the repair and reinforcement of bridge structures was discussed and verified. Experiments have verified that with the increase of fiber content, the flexural strength and compressive strength of magnesium phosphate cement-based nanocomposites in the repair and reinforcement of bridge structures gradually increase, and the tensile strength and flexural strength are increased by $25 \%$ compared with ordinary materials.

\section{Data Availability}

No data were used to support this study.

\section{Conflicts of Interest}

The author declares that there are no conflicts of interest.

\section{Acknowledgments}

This study was financially supported by the National Natural Science Foundation of China (50808096 and 50978128) and the Fundamental Research Funds for the Central Universities (lzujbky-2015-173).

\section{References}

[1] Y. Tang, W. Feng, W. X. Feng, J. Chen, D. Bao, and L. Li, "Compressive properties of rubber-modified recycled aggregate concrete subjected to elevated temperatures," Construction and Building Materials, vol. 268, 2020.

[2] R. Pang, B. Xu, Y. Zhou, X. Zhang, and X. Wang, "Fragility analysis of high CFRDs subjected to mainshock-aftershock sequences based on plastic failure," Engineering Structures, vol. 206, Article ID 110152, 2020.

[3] H. Feng, G. Chen, D. Gao, K. Zhao, and C. Zhang, "Mechanical properties of steel fiber-reinforced magnesium phosphate cement mortar," Advances in Civil Engineering, vol. 2018, no. 1, 11 pages, Article ID 3978318, 2018.

[4] L. Chong, C. Shi, J. Yang, and H. Jia, "Effect of limestone powder on the water stability of magnesium phosphate cement-based materials," Construction and Building Materials, vol. 148, no. 1, pp. 590-598, 2017.

[5] M. R. Ahmad, B. Chen, and J. Yu, "A comprehensive study of basalt fiber reinforced magnesium phosphate cement incorporating ultrafine fly ash," Composites Part B: Engineering, vol. 168, no. 1, pp. 204-217, 2019.

[6] K. J. Peters, I. K. Tragazikis, and P. T. Dalla, "Nondestructive evaluation of the mechanical behavior of cement-based nanocomposites under bending," in Proceedings of SPIE-The International Society for Optical Engineering, vol. 9436, no. 3, pp. 923-964, San Diego, CA, USA, March 2015.

[7] M. Selvakumar, S. K. Jaganathan, G. B. Nando, and S. Chattopadhyay, "Synthesis and characterization of novel polycarbonate based polyurethane/polymer wrapped hydroxyapatite nanocomposites: mechanical properties, osteoconductivity and biocompatibility," Journal of Biomedical Nanotechnology, vol. 11, no. 2, pp. 291-305, 2015.

[8] A. M. Díez-Pascual and A. L. Díez-Vicente, "Wound healing bionanocomposites based on Castor oil polymeric films reinforced with chitosan-modified $\mathrm{ZnO}$ nanoparticles," Biomacromolecules, vol. 16, no. 9, pp. 2631-2644, 2015.

[9] H. Li, T. Du, and H. Xiao, "Crystallization of calcium silicate hydrates on the surface of nanomaterials," Journal of the American Ceramic Society, vol. 100, no. 5, pp. 3227-3238, 2017.

[10] G. Riccardo, G. Chiara, B. Gloria et al., "Graphene-based nanomaterials for tissue engineering in the dental field," Nanomaterials, vol. 8, no. 5, pp. 349-350, 2018.

[11] Y. Li, W. Bai, and T. Shi, "A study of the bonding performance of magnesium phosphate cement on mortar and concrete," Construction and Building Materials, vol. 142, no. 1, pp. 459-468, 2017.

[12] S. Xu, J. Liu, and Q. Li, "Mechanical properties and microstructure of multi-walled carbon nanotube-reinforced cement paste," Construction and Building Materials, vol. 76, no. 1, pp. 16-23, 2015.

[13] H. S. Oh, H. Jee, and A. Baev, "Dramatic structural enhancement of chirality in photopatternable nanocomposites of chiral poly(fluorene-alt-benzothiadiazole) (PFBT) in achiral SU-8 photoresist," Advanced Functional Materials, vol. 22, no. 24, pp. 5074-5080, 2015.

[14] A. Hakamy, F. U. A. Shaikh, and I. M. Low, "Thermal and mechanical properties of $\mathrm{NaOH}$ treated hemp fabric and calcined nanoclay-reinforced cement nanocomposites," Materials \& Design, vol. 80, no. 7, pp. 70-81, 2015.

[15] N. K. Young, "Characterization and antimicrobial efficacy of Portland cement impregnated with silver nanoparticles," Journal of Advanced Prosthodontics, vol. 9, no. 3, pp. 217-223, 2017.

[16] S.-J. Kwon, H.-S. Lee, S. Karthick, V. Saraswathy, and H.-M. Yang, "Long-term corrosion performance of blended cement concrete in the marine environment-a real-time study," Construction and Building Materials, vol. 154, no. 15, pp. 349-360, 2017.

[17] Y. Tang, S. Fang, J. Chen, L. Ma, L. Li, and X. Wu, “Axial compression behavior of recycled-aggregate-concrete-filled gfrp-steel composite tube columns," Engineering Structures, vol. $216,2020$.

[18] M. Birenboim, R. Nadiv, A. Alatawna et al., "Reinforcement and workability aspects of graphene-oxide-reinforced cement nanocomposites," Composites Part B: Engineering, vol. 161, no. 15, pp. 68-76, 2019.

[19] J. Luo, C. Zhang, Z. Duan et al., "Surfactant-assisted processing of carbon nanotube cement-based nanocomposites: microstructural, electrical, and mechanical properties," Nanoscience and Nanotechnology Letters, vol. 10, no. 2, pp. 237-243, 2018.

[20] A. Hakamy, F. U. A. Shaikh, and I. M. Low, "Effect of calcined nanoclay on the durability of $\mathrm{NaOH}$ treated hemp fabricreinforced cement nanocomposites," Materials \& Design, vol. 92, no. 7, pp. 659-666, 2016.

[21] D. Feldman, "Lignin nanocomposites," Journal of Macromolecular Science, Part A, vol. 53, no. 6, pp. 382-387, 2016.

[22] P. Wang, T. Yao, Z. Li et al., "A superhydrophobic/electrothermal synergistically anti-icing strategy based on graphene composite," Composites Science and Technology, vol. 198, Article ID 108307, 2020. 
[23] L.-l. Wang, X. Dong, X.-r. Wang, G.-y. Zhu, H.-q. Li, and D.-j. Wang, "High performance long chain polyamide/calcium silicate whisker nanocomposites and the effective reinforcement mechanism," Chinese Journal of Polymer Science, vol. 34, no. 8, pp. 991-1000, 2016.

[24] D. Pinto, L. Bernardo, A. Amaro, and S. Lopes, "Mechanical properties of epoxy nanocomposites using titanium dioxide as reinforcement-a review," Construction and Building Materials, vol. 95, no. 8, pp. 506-524, 2015.

[25] M. A. Haque and B. Chen, "Research progresses on magnesium phosphate cement: a review," Construction and Building Materials, vol. 211, no. 30, pp. 885-898, 2019.

[26] Z. Jiang, L. Zhang, T. Geng, Y. Lai, W. Zheng, and M. Huang, "Study on the compressive properties of magnesium phosphate cement mixing with eco-friendly coir fiber considering fiber length," Materials, vol. 13, no. 14, Article ID 3194, 2020.

[27] L. Lv, P. Huang, L. Mo, M. Deng, J. Qian, and A. Wang, "Properties of magnesium potassium phosphate cement pastes exposed to water curing: a comparison study on the influences of fly ash and metakaolin," Construction and Building Materials, vol. 203, no. 10, pp. 589-600, 2019.

[28] K. Yamamoto, H. Shichiri, T. Ishida et al., "Effects of ascorbyl2-phosphate magnesium on human keratinocyte toxicity and pathological changes by sorafenib," Biological an Pharmaceutical Bulletin, vol. 40, no. 9, pp. 1530-1536, 2017.

[29] A. Pedone, F. Palazzetti, and V. Barone, "Models of aged magnesium-silicate-hydrate cements based on the lizardite and talc crystals: a periodic DFT-GIPAW investigation," Journal of Physical Chemistry C, vol. 121, no. 13, pp. 73197330, 2017.

[30] G. Guan and W. Zhao, "Research progress of fiber-reinforced cement matrix composites," China Silicate Bulletin, vol. 10, pp. 3342-3346, 2017.

[31] Y. Li, Y. Su, and J. Mei, "Research progress of Magnesium phosphate cement (MPC) and its application as FRP binder," Chinese Journal of Silicate, vol. 38, no. 3, pp. 76-80, 2019.

[32] S. Chen, M. K. Hassanzadeh-Aghdam, and R. Ansari, "An analytical model for elastic modulus calculation of $\mathrm{SiC}$ whisker-reinforced hybrid metal matrix nanocomposite containing SiC nanoparticles," Journal of Alloys and Compounds, vol. 767, pp. 632-641, 2018.

[33] S. Qu, L. Zhao, and Z. Xiong, "Cross-layer congestion control of wireless sensor networks based on fuzzy sliding mode control," Neural Computing \& Applications, vol. 32, no. 17, pp. 13505-13520, 2020.

[34] M. Shi, M. Narayanasamy, C. Yang et al., "3D interpenetrating assembly of partially oxidized MXene confined Mn-Fe bimetallic oxide for superior energy storage in ionic liquid," Electrochimica Acta, vol. 334, Article ID 135546, 2020.

[35] W. Wu, S. An, C. H. Wu, S. B. Tsai, and K. Yang, "An empirical study on green environmental system certification affects financing cost of high energy consumption enterprisestaking metallurgical enterprises as an example," Journal of Cleaner Production, vol. 244, 2020. 